\title{
Self-assembly of iron TCPP (meso-tetra(4-carboxyphenyl) porphyrin) into a chiral 2D coordination polymer
}

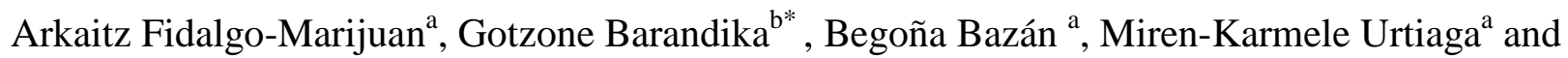 \\ María-Isabel Arriortua ${ }^{\mathrm{a}}$ \\ a Departamento de Mineralogía y Petrología, Facultad de Ciencia y Tecnología, Universidad del País \\ Vasco (UPV/EHU) / Apdo. 644, 48080 Bilbao, (Spain). E-mail: arkaitz.fidalgo@ehu.es, \\ bego.bazan@ehu.es, karmele.urtiaga@ehu.es, maribel.arriortua@ehu.es
}

\author{
b Departamento de Química Inorgánica, Facultad de Farmacia, Universidad del País Vasco \\ (UPV/EHU) / Paseo de la Universidad, 7, 01006 Vitoria-Gasteiz, (Spain). Phone: +34-945-013-080; \\ Fax: +34-945-013-014. E-mail: gotzone.barandika@ehu.es \\ * Corresponding author
}

\begin{abstract}
Synthetic metalloporphyrin complexes are often used as analogues of natural systems, and they can be used for the preparation of high-dimensional coordination polymers. In this work, a new chiral FeTCPP (TCPP is meso-tetra-(4-carboxyphenyl)porphyrin) coordination compound has been synthesised and structurally characterized. The compound is $2 \mathrm{D}$ via coordination bonds, and it exhibits strong hydrogen bonds that connect the planar arrays forming the 3D framework. The oxidation of the original $\mathrm{Fe}^{\mathrm{II}}$ ions to $\mathrm{Fe}^{\mathrm{III}}$ accounts for the formation of this array, in which the topological analysis reveals a very high connectivity based on a simple extension fashion of the structure. DFT calculations have been also carried out to study the stabilisation of the $\mathrm{Fe}^{\mathrm{III}}$-compound. This is the third example of a 2D coordination compound based on TCPP in which the dimensionality refers just to coordination bonds, and no other ligands are present in the structure.
\end{abstract}

Keywords: Supramolecular chemistry, chirality, DFT calculations, oxidation.

(C) 2011. This manuscript version is made available under the CC-BY-NC-ND 4.0 license http://creativecommons.org/licenses/by-nc-nd/4.0/ 


\section{Introduction}

Coordination polymers are also known as MOFs (metal organic frameworks), and the work devoted to this field in the last decades is huge. In this context, metalloporphyrins are remarkable precursors in supramolecular chemistry, giving rise to various architectures and properties [1-4]. To illustrate this point, several examples can be cited as photodynamic therapy, information storage devices, photoelectrical devices as photocells and light-emitting diodes (that transform energy in both directions), and receptors (exploiting their ability to selectively form complexes which can sharply change the spectral properties) [5-8].

Metalloporphyrins are one of the cornerstones on which the existence of life is based and major biochemical, enzymatic, and photochemical functions depend on the special properties of a tetrapyrrolic macrocycle. This is the reason why synthetic metalloporphyrin complexes are often used as analogues of natural systems found in photosynthesis, oxygen carriers, and catalysts [5] [9-14]. For instance, these systems are used to understand the mechanism of electron transfer through intermolecular interactions, and some works show that efficient energy transfer may occur across the intermolecular bonds [15-19].

From the point of view of coordination chemistry, the dimensionality of metalloporphyrin frameworks is defined by the extension of a structural unit in one, two or the three dimensions of the space via coordination bonds. Thus, axial coordination of metalloporphyrins represents a limiting factor for high dimensionality as it gives only one or two binding sites with other structural units. Therefore, additional binding centers are required for high dimensional frameworks, and one way to create them consists of incorporating additional donors at the periphery of a porphyrinic cycle. An illustrative example of the later is tetra-(4-carboxyphenyl)porphyrin (TCPP) (Scheme I) for which the presence of carboxylic groups at the 4-positions of the phenyl ring increases the possibilities of obtaining a high dimensional framework.

TCPP coordination polymers with different structures have been prepared. For example, 2D porphyrin frameworks have been reported exhibiting square grid structure sustained by characteristic $\pi-\pi$ stacking interactions and multiple hydrogen bonds [20-23]. Similarly, a 2D complex with $\mathrm{Mn}^{\mathrm{II}}$ [24] must be cited as the dimensionality is based on coordination bonds. Additionally, the combination of TCPP with other components gives rise to a variety of 2D and 3D structures [25]. Some of these combinations are specially remarkable as they include fullerene [26], silica [27] and 4,4'-bipyridine [28-29].

During the last years, our research has been focused on the preparation of coordination polymers with increasing dimensionality with a variety of metal-ligand combinations, and we have prepared several high dimensional structures with 4,4'-bipyridine, including interpenetrated networks [30-35]. In this sense, it is worth mentioning that, when combining an O-donor ligand like TCPP, with a N-donor one, like 4,4'-bipyridine, the Pearson acidity is one of the leading forces to be considered in the extension of the structure, as it is in relationship with the affinity of the metal centre, which is influenced by its oxidation state. The most popular example of a natural system where the oxidation state of the metal is crucial is the oxygen transport in haemoglobin.

Taking into account the above mentioned aspects, we intended to prepare $\mathrm{Fe}^{\mathrm{II}}$-porphyrin frameworks with TCPP and 4,4'-bipyridine. In particular, the goal of this work was to study the influence of the synthesis conditions on the structural features of the framework. In this way, this work presents the 
microwave-assisted hydrothermal synthesis of the new compound [FeTCPP], and its X-ray structural characterisation. From the point of view of the coordination binding, the structure is $2 \mathrm{D}$, and exhibits robust hydrogen bonds that connect the planar moieties giving rise to the 3D framework. A topological analysis and DFT calculations have been also carried out in order to analyze the self-assembly process.

\section{Experimental}

\subsection{Materials and methods}

The porphyrin compound TCPP (Sigma-Aldrich) and all the others solvents and reagents (SigmaAldrich) were obtained commercially and used without further purification. [FeTCPP] compound was synthesized by using microwave-assisted hydrothermal synthesis. Free ligand TCPP (4.7 mg, 0.006 mmol) was dissolved in a mixture of deionised water $(10 \mathrm{~mL})$ and acetone $(15 \mathrm{~mL})$, then under continuous stirring $\mathrm{NaOH}(1 \mathrm{M})$ was added until $\mathrm{pH}=14$ (to cause the porphyrin deprotonation). $\mathrm{FeCl}_{2}$ (7.6 mg, $0.06 \mathrm{mmol}$ ) dissolved in deionised water $(5 \mathrm{~mL})$ was added to porphyrin solution and after 10 minutes of stirring, 4,4'-bipyridine $(2.8 \mathrm{mg}, 0.018 \mathrm{mmol})$ dissolved in deionised water $(10 \mathrm{~mL})$ was added drop by drop. The solution was heated at $140{ }^{\circ} \mathrm{C}(800 \mathrm{~W})$ for $2 \mathrm{~h}$ in a CEM MARS5 microwave and after that, at the same temperature in a PTFE-lined stainless steel pressure vessel for 5 days in a conventional heater, yielding diffraction quality dark red crystals.

\subsection{Infrared spectroscopy}

The IR spectrum was collected on a JASCO FT/IR-6100 at room temperature at the range of 4000 to $400 \mathrm{~cm}^{-1}$, in $\mathrm{KBr}$ pellets (1\%).

\subsection{Single-crystal $X$-ray diffraction}

Rhombohedral single-crystals with dimensions given in Table 1 were selected under polarizing microscope and mounted on MicroMounts. Single-crystal X-ray diffraction data were collected at 100K on a Bruker X8 Prospector equipped with a high brilliance Cu-IMS (microfocus source) and APEX II detector. Details of crystal data and some features of the structure refinement are reported in Table 1. Lattice constants were obtained by using a standard program belonging to the software of the diffractometer, confirming at the same time the good quality of the single-crystal.

The Lorentz-polarization and absorption corrections were made with the diffractometer software, taking into account the size and shape of the crystals [36]. The structure of [FeTCPP] was solved by direct methods with the SHELXS-97 [37] program, in the monoclinic P $2{ }_{1}$ space group, which allowed us to obtain the position of the Fe atom, as well as oxygen and nitrogen atoms and some of the carbon atoms of the TCPP molecule. The refinement of the crystal structures was performed by full matrix least-squares based on $F^{2}$, using the SHELXL-97 program [37], obtaining the remaining carbon atoms. Anisotropic thermal parameters were used for all non-hydrogen atoms. All the hydrogen atoms, both

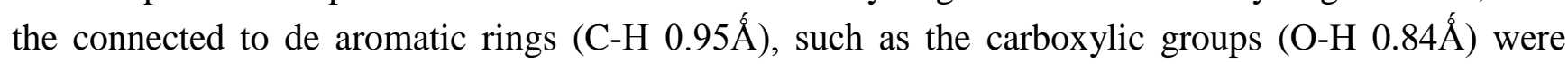
fixed geometrically after having detected their existence on the density map and were refined using a riding model with common isotropic displacements. Final R-factors are given in Table 1 together with other crystallographic data, the conditions employed at the measurement of diffracted intensities and others characteristics of the refinement. 
The diffraction data (intensity statistics and systematic absences), as well as the phase determination and structure solution processes, were consistent only with the non-centrosymmetric space group P 2 , with two screw-related porphyrin molecules per unit-cell.

\subsection{Computational details}

Density functional calculations were carried out by using the GAUSSIAN03 package [38] and the hybrid density functional B3LYP. The split-valence basis set 6-31G was used for all the calculations.

\section{Results and Discussion}

Microwave-assisted synthesis was employed for the preparation of a new coordination polymer. Its chemical formula is [FeTCPP], where the oxidation state of iron is 3 , and $\mathrm{TCPP}^{-3}$ is the trivalent anion formed from deprotonation of meso-tetra-(4-carboxyphenyl)porphyrin $\left(\mathrm{C}_{48} \mathrm{H}_{30} \mathrm{~N}_{4} \mathrm{O}_{8}\right)$. The fact that the original $\mathrm{Fe}^{\mathrm{II}}$ has suffered oxidation to $\mathrm{Fe}^{\mathrm{III}}$ will be discussed latter. The absence of the ligand 4,4'bipyridine in the structure will be also commented. Structural characterization of [FeTCPP] was carried out by means of IR spectroscopy and X ray diffraction.

\subsection{Structural characterization}

\subsubsection{IR spectroscopy}

IR data show significant differences between the free ligand TCPP and the metallated [FeTCPP] compound. The N-H bond stretching and bending frequencies of TCPP located at $3200 \mathrm{~cm}^{-1}$ and 970 $\mathrm{cm}^{-1}$ disappeared when iron ion was inserted into the porphyrin ring, and a characteristic Fe-N band appears at $1000 \mathrm{~cm}^{-1}$, which indicates the formation of an iron porphyrin compound [39]. The bands at about $3415 \mathrm{~cm}^{-1}, 1740 \mathrm{~cm}^{-1}$ and $1200 \mathrm{~cm}^{-1}$ were assigned to the $\mathrm{O}-\mathrm{H}, \mathrm{C}=\mathrm{O}$ and $\mathrm{C}-\mathrm{O}$ bonds of the carboxylic groups, respectively. The band at $2940 \mathrm{~cm}^{-1}$ was assigned to the $\mathrm{C}-\mathrm{H}$ bond of the benzene and pyrrole rings. The bands at $1690-1540 \mathrm{~cm}^{-1}$ and $1380 \mathrm{~cm}^{-1}$ were assigned to $\mathrm{C}=\mathrm{C}$ stretching mode and the $\mathrm{C}-\mathrm{N}$ stretching vibration, respectively. A weak band corresponding to the Fe-O bond stretching mode was observed at about $820 \mathrm{~cm}^{-1}$. Finally, the band at $790 \mathrm{~cm}^{-1}$ was assigned to the $\mathrm{H}$ out of plane bending of the $\mathrm{C}-\mathrm{H}$ bond.

\subsubsection{Crystal structure of [FeTCPP]}

The crystal structure of [FeTCPP] consists of tetrapyrrole units containing the Fe atoms as shown in Figure 1. The metal atoms are octahedrally coordinated to four N atoms (N1, N2, N3 and N4) that are coplanar. The axial positions are occupied by two $\mathrm{O}$ atoms (O1 and $\mathrm{O} 6)$ that belong to the carboxylate groups of adjacent porphyrin units. Table 2 summarizes the most significant bond parameters for [FeTCPP]. As observed, the values lie among the typical ones for octahedral iron(III). In fact, the only remarkable feature is that Fe-O6 bond is slightly longer than the others.

Taking the structural fragment on Figure 1 as reference, the polymer extends through the formation of four new bonds with adjacent porphyrin groups, involving $\mathrm{O} 1$ and $\mathrm{O} 6$ atoms. Thus, the reference porphyrin uses its own $\mathrm{O} 1$ and $\mathrm{O} 6$ atoms to connect with another two porphyrin units. This is, each unit is connected to four equivalent units, and the result is a 2D array (Figure 2). This planar array is 
based on the fact that octahedral spheres are rotated forming planes that are perpendicular to the [10-1] direction, the extension of the structure taking place through coordination bonds. It is worth pointing out that this array is chiral. Additionally, there are several hydrogen bonds (Table 3 ) between atoms on the same plane, $(\mathrm{O} 5-\mathrm{H} 50 \cdots \mathrm{O} 3)$ and $(\mathrm{O} 8-\mathrm{H} 80 \cdots \mathrm{O} 2)$, that reinforce the robustness of the 2D moiety.

As shown in Figure 3, packing on the planes along the [10-1] direction gives rise to the 3D framework. These planes are chemically connected through strong hydrogen bonds between $\mathrm{O} 2$ and $\mathrm{O} 4$ atoms where $d(\mathrm{O} 4-\mathrm{H} 40 \cdots \mathrm{O} 2)=2.614(4) \AA$. As a consequence of this packing fashion, the 3D framework keeps chirality. Undoubtedly, this is a remarkable fact for [FeTCPP], since this property is not usual for structures based on porphyrin blocks exhibiting $\mathrm{D}_{4 \mathrm{~h}}$ molecular symmetry [5]. Obviously, the fact that the structure extends through both axial sites and two of the equatorial ones is responsible for the later.

\subsection{Topological analysis}

The topological analysis has been carried out by means of TOPOS software [40]. First of all, the topology of the planes has been determined just considering the node connections taking place through coordination bonds (Figure 4). The result is a uninodal 4-c net (sql/Shubnikov tetragonal plane net $\left\{4^{4} ; 6^{2}\right\}$ ). Several examples of compounds exhibiting the same topology can be found in literature [4146].

The fact that such a complicated structure extends in that simple fashion is remarkable, as well as the fact that for [FeTCPP] the extension of the structure takes place through two of the four equatorial positions and both axial ones.

If considering now the extension of the structure in the third dimension of the space, the topology shown in Figure 5 includes connections between hydrogen bonds that take place for Fe atoms at a distance of $14.132 \AA$. The resulting uninodal net is 6 -c type (mab $\left\{4^{4} ; 6^{10} ; 8\right\}$ ). This net has been reported for just one compound [47].

It is worth mentioning that there is a shorter interlayer distance between Fe atoms at $11.092 \AA$, but these atoms remain unconnected. Additionally, if considering the intralayer connections through hydrogen bonds, the net connectivity increases since there are two more links for each iron node at $8.893 \AA$. The resulting uninodal net is $8-c\left(3^{6} ; 4^{10} ; 5^{11} ; 6\right)$, and no examples have been found in literature illustrating this new topology.

\subsection{Stability of the metallated TCPP}

The stability of the metallated monomers cannot be separated from two facts: the oxidation of the iron ions, and the $\mathrm{pH}$ variation along the synthesis.

The oxidation state of iron atoms in [FeTCPP] was corroborated by using the PLATON [48] software (Brown method) [49,50]. A calculated value of 2.954 was obtained that is in accordance with the presence of $\mathrm{Fe}^{\mathrm{III}}$ ions. However, $\mathrm{Fe}^{\mathrm{II}}$ was used for the synthesis, indicating that the metal ions have suffered oxidization.

Additionally, an asymmetric location of hydrogen atoms is observed for porphyrin in [FeTCPP]. This is, both hydrogen atoms in pyrrole groups have been removed, as well as one of the four hydrogen atoms on the carboxylates. This is a striking location that results in the $\mathrm{TCPP}^{-3}$ anion. In order to understand this process, the charges on the electronegative atoms in isolated porphyrin were calculated 
by means of the Hückel method. The results indicate that, as expected, the most acid hydrogen atoms are those located on the carboxylate groups. In fact, values close to -0.70 and -0.15 have been calculated for the $\mathrm{O}$ atoms on $-\mathrm{CO}$ and - $\mathrm{OH}$ groups, respectively. On the other hand, iminic $\mathrm{N}$ atoms exhibit negative charges ( -0.41 for $\mathrm{N} 2$ and -0.41 for $\mathrm{N} 4)$, and pyrrolic ones positives values $(+0.39$ for $\mathrm{N} 1$ and +0.38 for N3). Nevertheless, in [FeTCPP] the ligand keeps three of the four most acid hydrogen atoms.

In order to understand these two facts, HF energies were calculated. The selected structural unit consists of a [FeTCPP $]^{n}$ monomer, where $n$ is the charge that depends on the oxidation state of the metal ion and the charge of TCPP. Obviously, at high $\mathrm{pH}$ values, TCPP is completely deprotonated $\left(\mathrm{TCPP}^{-6}\right)$. The as-done DFT calculations (B3LYP / 6-31G) were carried out by using the GAUSSIAN 03 software [38]. The results (Table 4) suggest that the oxidation takes place at basic $\mathrm{pH}$, when TCPP is completely deprotonated. Then, as $\mathrm{pH}$ goes to neutral values, the porphyrin recovers three of the acid protons that get located on the carboxylates. Additionally, the fact that $\left[\mathrm{FeTCPP}^{-1}\right.$ (with $\mathrm{Fe}^{\mathrm{II}}$ ) is more stable than [FeTCPP] (with $\mathrm{Fe}^{\mathrm{III}}$ ) also indicates that the $\mathrm{Fe}^{\mathrm{III}}$-monomers should not exist at neutral $\mathrm{pH}$ values. In other words, the $[\mathrm{FeTCPP}]^{\mathrm{n}}$ unit with $\mathrm{Fe}^{\mathrm{III}}$ becomes neutral at a higher $\mathrm{pH}$ value than the unit with $\mathrm{Fe}^{\mathrm{II}}$, provoking the precipitation of the final product with $\mathrm{Fe}^{\mathrm{III}}$. The later is in complete agreement with the Pearson theory. Therefore, if admitting that the presence of $\mathrm{Fe}^{\mathrm{III}}$ accounts for the polymerization of the monomers via carboxylate groups, it is easy to understand that $4,4^{\prime}$ bipyridine is not a component of the final product.

Finally, it must be pointed out that this is the third example [24] [51] of a 2D coordination compound based on TCPP in which the dimensionality refers just to coordination bonds, and no other ligands are present in the structure.

\section{Conclusions}

A new Fe-TCPP coordination polymer has been prepared in which 2D arrays are formed via coordination bonds. The stabilization of the metallated monomers at a basic $\mathrm{pH}$ value accounts for the oxidation of $\mathrm{Fe}^{\mathrm{II}}$ to $\mathrm{Fe}^{\mathrm{III}}$, and explains the polymerization of the monomers via carboxylate groups. As a result, a rare framework has been obtained in which the 2D topology follows a very simple extension fashion. The three-dimensionality is raised via hydrogen bonds that keep the chirality found for the 2D coordination array. This is the third example of a 2D coordination compound based on TCPP in which the dimensionality refers just to coordination bonds, and no other ligands are present in the structure.

\section{Acknowledgements}

This work has been financially supported by the "Ministerio de Ciencia e Innovación” (MAT201015375) and the "Gobierno Vasco" (Basque University System Research Groups, IT-177-07) which we gratefully acknowledge. SGIker technical support (MEC, GV/EJ, European Social Fund) is gratefully acknowledged. The authors like to thank Dr. Holger Ott (Bruker AXS GmbH, Karlsruhe, Germany) for collecting the data of [FeTCPP] compound on a Bruker X8 Prospector equipped with a high brilliance Cu-IMS (microfocus source) and APEX II detector. A. Fidalgo thanks to the UPV/EHU fellowships and to Ainhoa Calderon for her invaluable help in this work.

\section{Appendix A. Supplementary data}


CCDC-825599 contains the supplementary crystallographic data for [FeTCPP]. These data can be obtained free of charge via http://www.ccdc.cam.ac.uk/conts/retrieving.html, or from the Cambridge Crystallographic Centre, 12 Union Road, Cambridge CB2 1EZ, UK; fax: (+44) 1223-336-033; or e mail: deposit@ccdc.cam.ac.uk. Supplementary data associated with this article can be found, in the online version, at doi: xxxx.

\section{References}

[1] I. Beletskaya, V.S. Tyurin, A.Y. Tsivadze, R. Guilard, C. Stern, Chem. Rev. 109 (2009) 16591713.

[2] C.M. Drain, A. Varotto, I. Radivojevic, Chem. Rev. 109 (2009) 1630-1658.

[3] A. Karmakar, I. Goldberg, CrystEngComm 12 (2010) 4095-4100.

[4] I. Goldberg, CrystEngComm 10 (2008) 637-645.

[5]: K.M. Kadish, K.M. Smith, R. Guilard, The Porphyrin Handbook, Academic Press, San Diego, 2000.

[6] M.G.H. Vicente, L. Jaquinod, K.M. Smith, Chem. Commun. (1999) 1771-1782.

[7] J. Wojaczynski, L. Latos-Grazynski, Coord. Chem. Rev. 204 (2000) 113-171.

[8] M.E. Kosal, K.S. Suslick, J. Solid State Chem. 152 (2000) 87-98.

[9] K.M. Smith, Porphyrins and Metaloporphyrins, Elsevier: Amsterdam, 1972.

[10] D. Dolphin, in: The Porphyrins, D. Dolphin (Ed.), Physical Chemistry, Part A, Academic Press New York, 1978, Volume 3.

[11] H. Yao, H. Sasahara, K. Kimura, Chem. Mater. 23 (2011) 913-922.

[12] D. Ecija, K. Seufert, D. Heim, W. Auwärter, C. Aurisicchio, C. Fabbro, D. Bonifazi, J.V. Barth, ACS Nano 4 (2010) 4936-4942.

[13] T. Kodaira, M. Yamamoto, T. Tanaka, M. Urushisaki, T. Hashimoto, Polymer 36 (1995) 37673773.

[14] G. Li, S. Bhosale, S. Tao, R. Guo, S. Bhosale, F. Li, Y. Zhang, T. Wang, J.H. Fuhrhop, Polymer 46 (2005) 5299-5307.

[15] L. Wei, D. Syomin, R.S. Loewe, J.S. Lindsey, F. Zaera, D.F. Bocian, J. Phys. Chem. B 109 (2005) 6323-6330.

[16] T.S. Balaban, N. Berova, C.M. Drain, R. Hauschild, X. Huan, H. Kalt, S. Lebedkin, J.M. Lehn, F. Nifaitis, G. Pescitelli, V.I. Prokhorenko, G. Riedel, G. Smeureanu, J. Zeller, Chem. Eur. J. 13 (2007) 8411-8427.

[17] M. Koepf, A. Trabolsi, M. Elhabiri, J.A. Wytko, D. Paul, A.M. Albrecht-Gary, J. Weiss, Org. Lett. 7 (2005) 1279-1282.

[18] J. Gitzel, H. Ohno, E. Tsuchida, D. Woehrle, Polymer 27 (1986) 1781-1787.

[19] W. Anannarukan, S. Tantayanon, D. Zhang, E.A. Aleman, D.A. Modarelli, F.W. Harris, Polymer 47 (2006) 4936-4945.

[20] S. George, I. Goldberg, Cryst. Growth Des. 6 (2006) 755-762.

[21] P. Dastidar, Z. Stein, I. Goldberg, C.E. Strouse, Supramol. Chem. 7 (1996) 257-270.

[22] Y. Diskin-Posner, R.K. Kumar, I. Goldberg, New J. Chem. 23 (1999) 885-890.

[23] W. Chen, S. Fukuzumi, Eur. J. Inorg. Chem. 36 (2009) 5494-5505.

[24] S. George, S. Lipstman, S. Muniappan, I. Goldberg, CrystEngComm, 8 (2006) 417-424. 
[25] Y. Diskin-Posner, G.K. Patra, I. Goldberg, Eur. J. Inorg. Chem. 10 (2001) 2515-2523.

[26] K.I. Matsuoka, T. Akiyama, S. Yamada, J. Phys. Chem. C 112 (2008) 7015-7020.

[27] H. Qiu, J. Xiez, S. Che, Chem. Commun. (2011) 2607-2609.

[28] E.Y. Choi, P.M. Barron, R.W. Novotny, H.T. Son, C. Hu, W. Choe, Inorg. Chem. 48 (2009) 426428

[29] Y. Diskin-Posner, S. Dahal, I. Goldberg, Angew. Chem. Int. Ed. 39 (2000) 1288-1292.

[30] R. Fernández de Luis, M.K. Urtiaga, J.L. Mesa, K. Vidal, L. Lezama, T. Rojo, M.I. Arriortua, Chem. Mater. 22 (2010) 5543-5553.

[31] Z.E. Serna, R. Cortés, M.K. Urtiaga, M.G. Barandika, L. Lezama, M.I. Arriortua, T. Rojo, Eur. J. Inorg. Chem. 3 (2001) 865-872.

[32] M.L. Hernández, M.K. Urtiaga, M.G. Barandika, R. Cortés, L. Lezama, N. De la Pinta, M.I. Arriortua, T. Rojo, Dalton Trans. 20 (2001) 3010-3014.

[33] S. Martin, M.G. Barandika, L. Lezama, J.L. Pizarro, Z.E. Serna, J.I. Ruiz De Larramendi M.I. Arriortua, T. Rojo, R. Cortés, Inorg. Chem. 40 (2001) 4109-4115.

[34] Z.E. Serna, L. Lezama, M.K. Urtiaga, M.I. Arriortua, M.G. Barandika, R. Cortés, T. Rojo, Angew. Chem. 39 (2000) 344-347.

[35] M.L. Hernández, M.G. Barandika, M.K. Urtiaga, R. Cortés, L. Lezama, M.I. Arriortua, J. Chem. Soc., Dalton Trans. 1 (2000) 79-84.

[36] W. Yinghua, J. Appl. Cryst. 20 (1987) 258-259.

[37] G.M. Sheldrick, Acta Cryst. A64 (2008) 112-122.

[38] Gaussian 03, Revision D.02, M. J. Frisch, G. W. Trucks, H. B. Schlegel, G. E. Scuseria, M. A. Robb, J. R. Cheeseman, J. A. Montgomery, Jr., T. Vreven, K. N. Kudin, J. C. Burant, J. M. Millam, S. S. Iyengar, J. Tomasi, V. Barone, B. Mennucci, M. Cossi, G. Scalmani, N. Rega, G. A. Petersson, H. Nakatsuji, M. Hada, M. Ehara, K. Toyota, R. Fukuda, J. Hasegawa, M. Ishida, T. Nakajima, Y. Honda, O. Kitao, H. Nakai, M. Klene, X. Li, J. E. Knox, H. P. Hratchian, J. B. Cross, V. Bakken, C. Adamo, J. Jaramillo, R. Gomperts, R. E. Stratmann, O. Yazyev, A. J. Austin, R. Cammi, C. Pomelli, J. W. Ochterski, P. Y. Ayala, K. Morokuma, G. A. Voth, P. Salvador, J. J. Dannenberg, V. G. Zakrzewski, S. Dapprich, A. D. Daniels, M. C. Strain, O. Farkas, D. K. Malick, A. D. Rabuck, K. Raghavachari, J. B. Foresman, J. V. Ortiz, Q. Cui, A. G. Baboul, S. Clifford, J. Cioslowski, B. B. Stefanov, G. Liu, A. Liashenko, P. Piskorz, I. Komaromi, R. L. Martin, D. J. Fox, T. Keith, M. A. Al- Laham, C. Y. Peng, A. Nanayakkara, M. Challacombe, P. M. W. Gill, B. Johnson, W. Chen, M. W. Wong, C. Gonzalez, J. A. Pople, Gaussian, Inc., Wallingford CT, 2004.

[39] Z.C. Sun, Y.B. She, Y. Zhou, X.F. Song, K. Li, Molecules 16 (2011) 2960-2970.

[40] http:// www.topos.ssu.samara.ru (05/05/2011) V.A. Blatov, IUCr CompComm Newsletter, 7 (2006) 4-38.

[41] Y. Xu, P.K. Chen, Y.X. Che, J.M. Zheng, Eur. J. Inorg. Chem. 34 (2010) 5478-5483.

[42] P. Kanoo, T.K. Maji, Eur. J. Inorg. Chem. 24 (2010) 3762-3769.

[43] S.R. Batten, K.S. Murray, Coord. Chem. Rev. 246 (2003) 103-130.

[44] F. Li, S. Luo, X. Li, T. Li, Inorg. Chem. Commun. 13 (2010) 656-658.

[45] M.N. Sokolov, E.V. Peresypkina, I.V. Kalinina, A.V. Virovets, V.S. Korenev, V.P. Fedin, Eur. J. Inorg. Chem. 34 (2010) 5446-5454. 
[46] R. Fernández de Luis, M.K. Urtiaga, J.L. Mesa, A.T. Aguayo, T. Rojo, M.I: Arriortua, CrystEngComm 12 (2010) 1880-1886.

[47] M.A. Braverman, R.L. LaDuca, CrystEngComm 10 (2008) 117-124.

[48] A.L. Spek, PLATON, A Multipurpose Crystallographic Tool; Utrecht University: Utrecht, The Netherlands, 1998.

[49] N.E. Brese, M. O’Keeffe, Acta Cryst. B47 (1991) 192-197.

[50] I.D. Brown, D. Altermatt, Acta Cryst. B41 (1985) 244-247.

[51] M. Shmilovits, M. Vinodu, I. Goldberg, New. J. Chem. 28 (2004) 223-227. 
Appendix B. Schemes, figures and tables

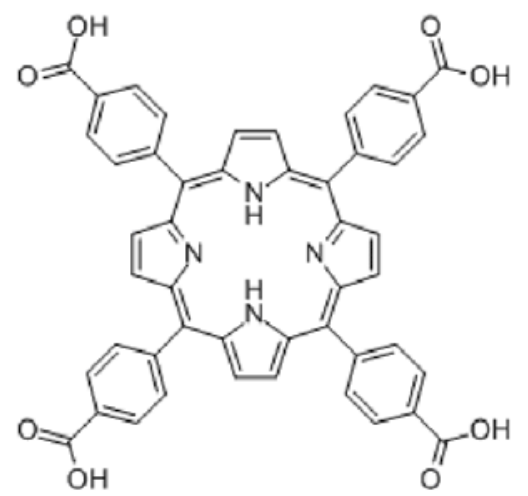

Scheme I. Lewis structure of TCPP.

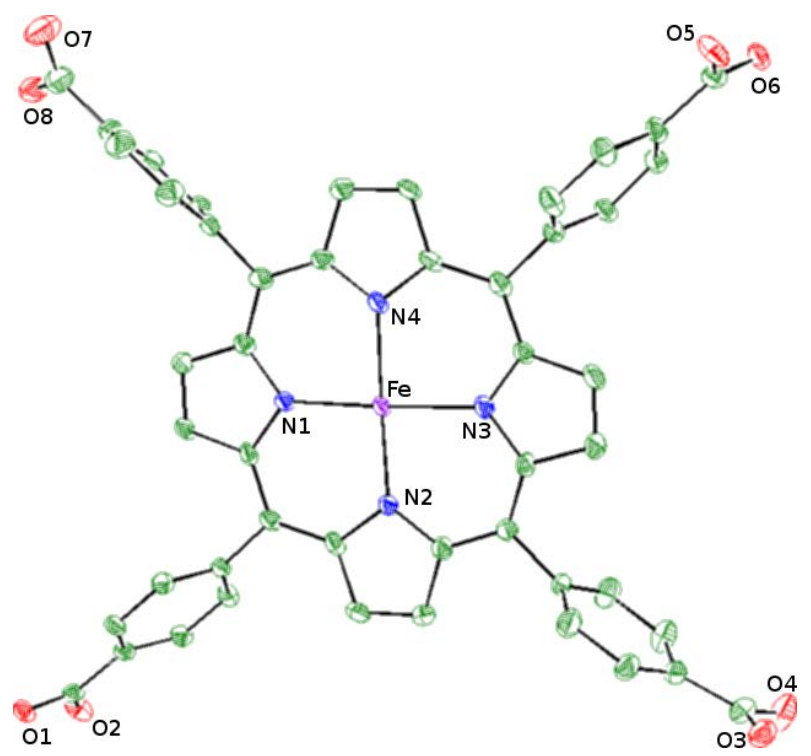

Figure 1. ORTEP detail of the equatorial plane for the octahedral coordination sphere in [FeTCPP] (Fe-purple, C-green, N-blue and O-red). 


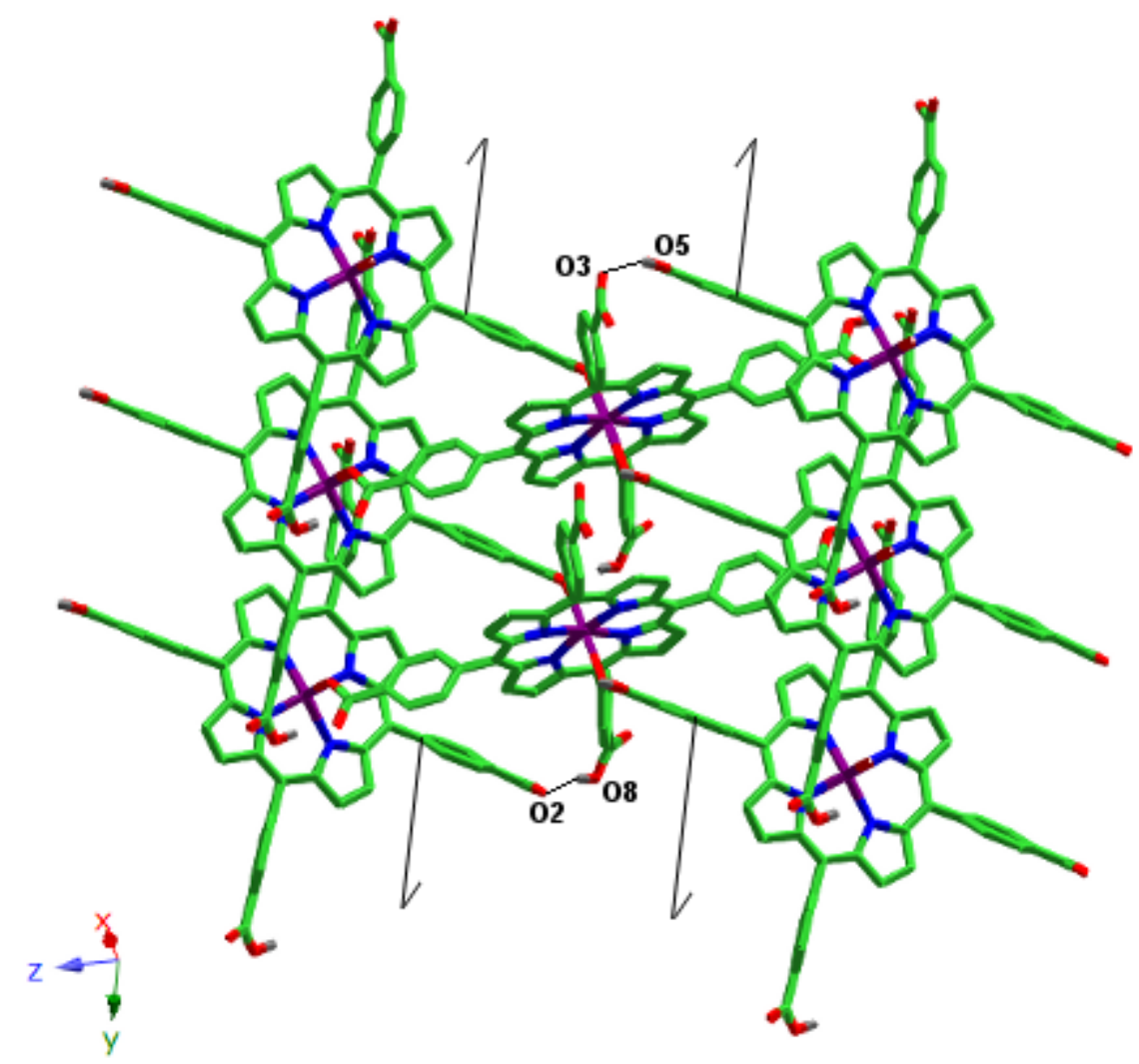

Figure 2. View of a layer for [FeTCPP] (Fe-purple, C-green, N-blue, O-red, H-grey). Intralayer hydrogen bonds are marked as black lines. 2-fold screw axes are located along the $b$-axis.

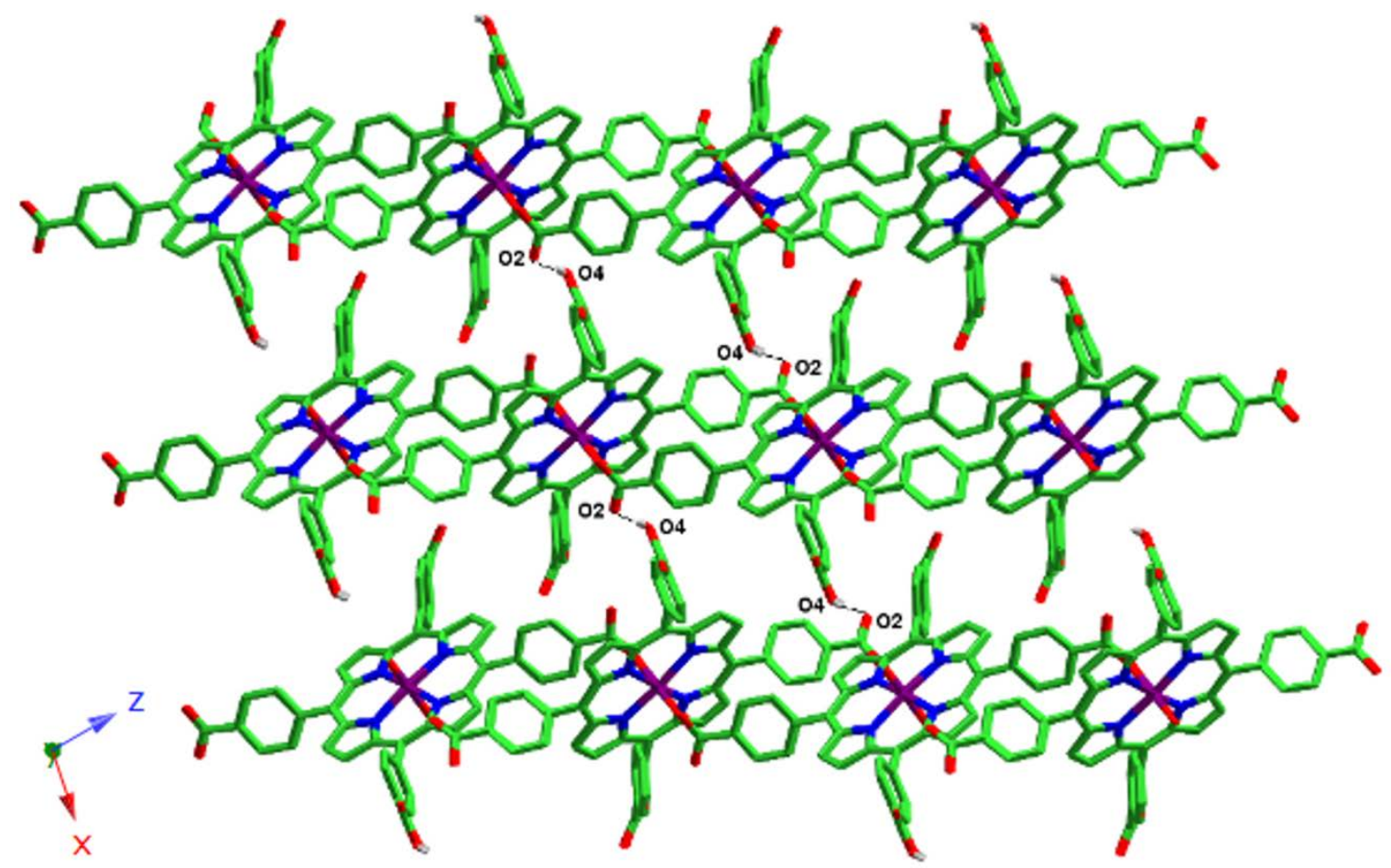

Figure 3. [010] projection of the 3D covalent array for [FeTCPP] (Fe-purple, C-green, Nblue, O-red, H-grey). Hydrogen bonds between the layers are marked as black lines. 


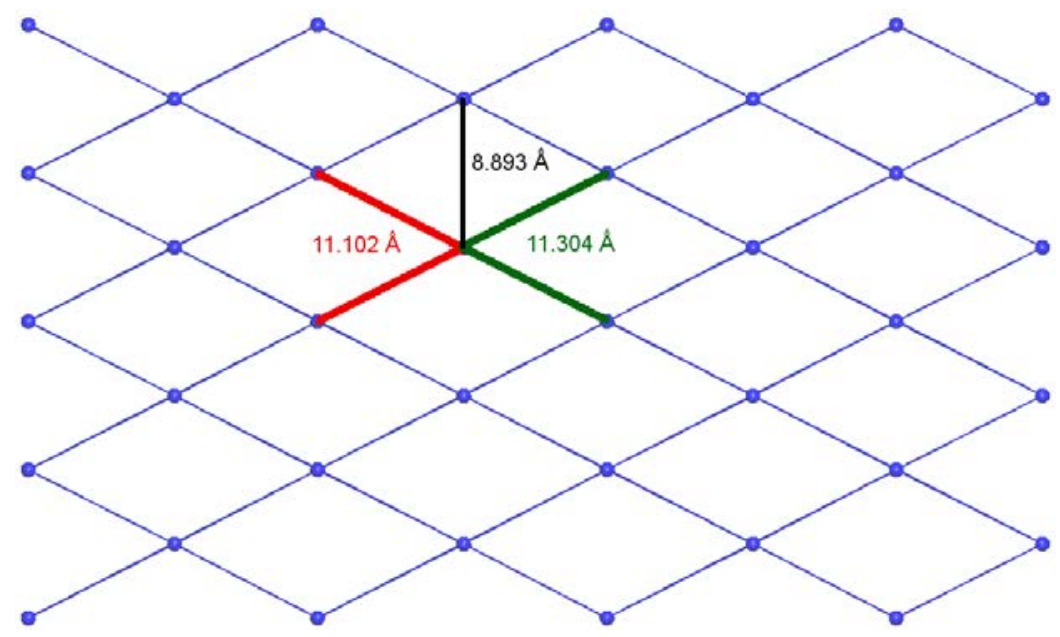

Figure 4. Topology of the 2D layers.

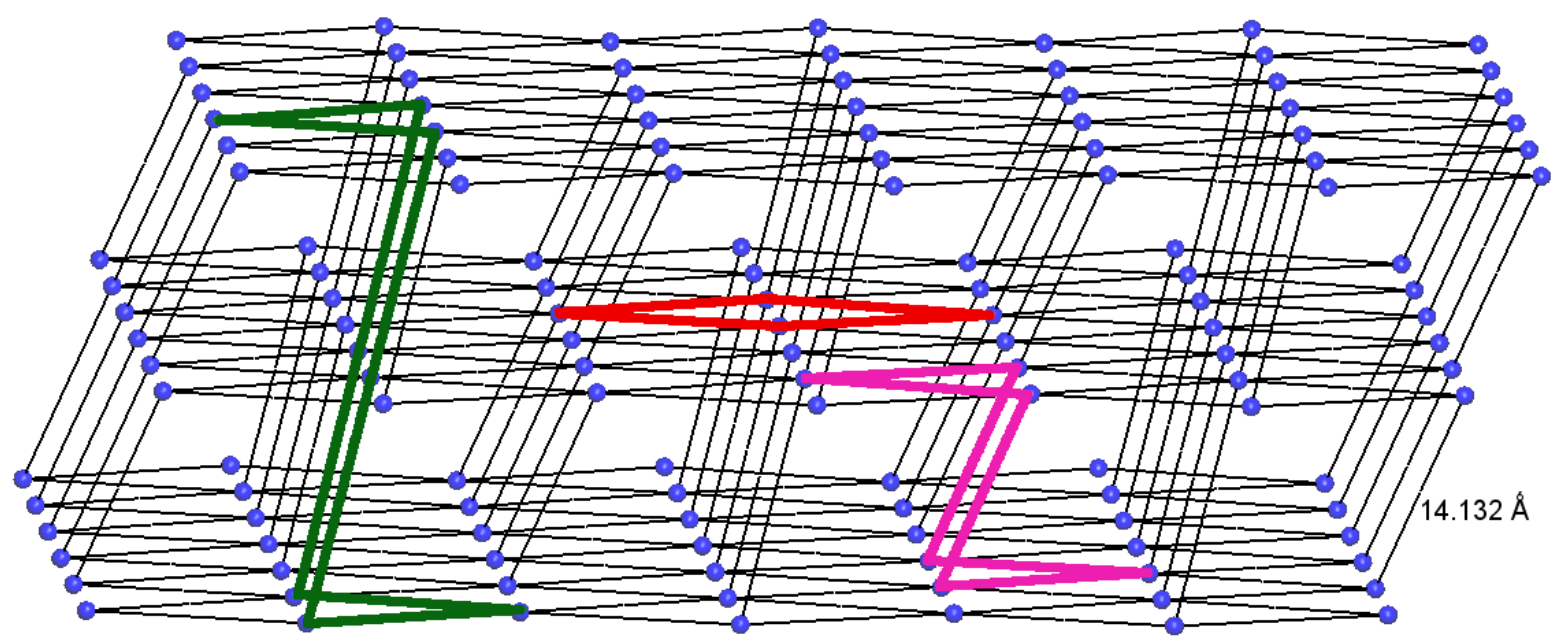

Figure 5. Topology of the 3D net. Four-, six-, and eight-member circuits are shown in red, pink, and green, respectively.

Table 1. Crystal data and structure refinement for [FeTCPP].

\begin{tabular}{|c|c|}
\hline & [FeTCPP] \\
\hline Formula & $\mathrm{C}_{48} \mathrm{H}_{27} \mathrm{FeN}_{4} \mathrm{O}_{8}$ \\
\hline $\mathrm{FW} / \mathrm{g} \mathrm{mol}^{-1}$ & 843.59 \\
\hline Crystal system & Monoclinic \\
\hline Space group & $\mathrm{P} 2{ }_{1}$ \\
\hline$a / \AA$ & $11.0195(2)$ \\
\hline$b / \AA \dot{~}$ & $8.8470(2)$ \\
\hline$c / \AA ̊$ & 20.0191(4) \\
\hline$\beta /^{\circ}$ & 102.902(2) \\
\hline$V / \AA^{3}$ & 1902.38(7) \\
\hline$Z, F(000), T / K$ & $2,866,100(2)$ \\
\hline$\mu / \mathrm{mm}^{-1}$ & 3.728 \\
\hline$\rho_{\text {calc } \cdot,} \rho_{\text {obs. }} / \mathrm{gr} \mathrm{cm}^{-3}$ & $1.473,1.478(4)$ \\
\hline Crystal size/ mm, colour & $0.36 \times 0.15 \times 0.01$, dark red \\
\hline Radiation $(\lambda / \AA)$ & 1.54178 \\
\hline
\end{tabular}


No. of reflections, Independent reflections

Limiting indices $h, k, l$

$\mathrm{R}_{\text {int }}, \mathrm{R}_{\sigma}$

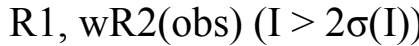

R1, wR2(all)

GOF $S$

No. of parameters/restraints

Largest diffraction peak and hole/e $\AA^{-3}$
20868, 6320

$-13 \leq h \leq 13$

$-9 \leq k \leq 10$

$-23 \leq l \leq 23$

$0.0480,0.0489$

$\mathrm{R} 1=0.0378, \mathrm{wR} 2=0.0877$

$\mathrm{R} 1=0.0475, \mathrm{wR} 2=0.0921$

1.026

554,1

$0.281,-0.235$

Table 2. Most significant angles $\left(^{\circ}\right)$ and distances $(\AA)$ for [FeTCPP] (distances in bold).

\begin{tabular}{c|cccccc}
\hline Fe & N1 & N2 & N3 & N4 & O1 & O6 \\
\hline O6 & $85.44(10)$ & $89.98(10)$ & $86.91(11)$ & $84.09(10)$ & $178.34(11)$ & $\mathbf{2 . 2 2 0 ( 3 )}$ \\
O1 & $95.62(11)$ & $88.74(11)$ & $92.03(11)$ & $97.18(11)$ & $\mathbf{1 . 9 8 8 ( 2 )}$ & \\
N4 & $90.15(11)$ & $174.07(13)$ & $89.35(11)$ & $\mathbf{2 . 0 6 0 ( 3 )}$ & & \\
N3 & $172.34(13)$ & $90.17(11)$ & $\mathbf{2 . 0 3 9 ( 3 )}$ & & & \\
N2 & $89.54(11)$ & $\mathbf{2 . 0 6 7 ( 3 )}$ & & & & \\
N1 & $\mathbf{2 . 0 3 0 ( 3 )}$ & & & & &
\end{tabular}

Table 3. Intra- and interlayer hydrogen bond parameters

\begin{tabular}{cccccc}
\hline $\mathrm{O}-\mathrm{H}$ & $\mathrm{A}(\mathrm{O})$ & $\mathrm{O}-\mathrm{H}(\AA)$ & $\mathrm{H} \cdots \mathrm{A}(\AA)$ & $\mathrm{O} \cdots \mathrm{A}(\AA)$ & $\mathrm{O}-\mathrm{H} \cdots \mathrm{A}\left({ }^{\circ}\right)$ \\
\hline $\mathrm{O}(4)-\mathrm{H}(40)$ & $\mathrm{O}(2)(2-x,-3 / 2+y,-z)$ & 0.84 & 1.78 & $2.614(4)$ & 171 \\
$\mathrm{O}(5)-\mathrm{H}(50)$ & $\mathrm{O}(3)(2-x, 1 / 2+y, 1-z)$ & 0.84 & 2.00 & $2.718(4)$ & 144 \\
$\mathrm{O}(8)-\mathrm{H}(80)$ & $\mathrm{O}(2)(1-x, 1 / 2+y,-z)$ & 0.84 & 1.91 & $2.740(4)$ & 169 \\
\hline
\end{tabular}

Table 4. Energy values (Hartree) for the selected structural units.

\begin{tabular}{|c|c|c|c|}
\hline Metal ion & Ligand & Monomer & HF energy \\
\hline $\mathrm{Fe}^{\mathrm{II}}$ & $\mathrm{TCPP}$ & {$[\mathrm{FeTCPP}]^{-1}$} & -3928.5387399 \\
\hline $\mathrm{Fe}^{\mathrm{III}}$ & $\mathrm{TCPP}^{-3}$ & {$[\mathrm{FeTCPP}]$} & -3928.4125033 \\
\hline $\mathrm{Fe}^{\mathrm{II}}$ & $\mathrm{TCPP}^{-6}$ & {$[\mathrm{FeTCPP}]^{-4}$} & -3926.7601369 \\
\hline
\end{tabular}




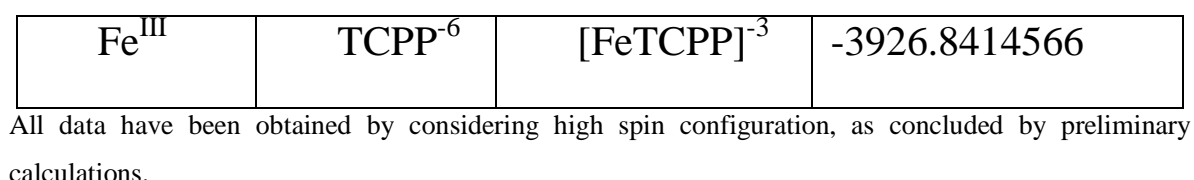

\section{Highlights}

$>$ We have synthesised a new chiral [Fe-TCPP] 2D coordination compound. $>$ The oxidation of Fe ${ }^{\mathrm{II}}$ to $\mathrm{Fe}^{\mathrm{III}}$ is in relationship with the polymerization of the monomers. $>$ A rare framework has been obtained in which the $2 \mathrm{D}$ topology follows a very simple extension fashion. $>$ This is the third example of a $2 \mathrm{D}$ coordination compound based on TCPP with no additional ligands. 
Graphical

abstract

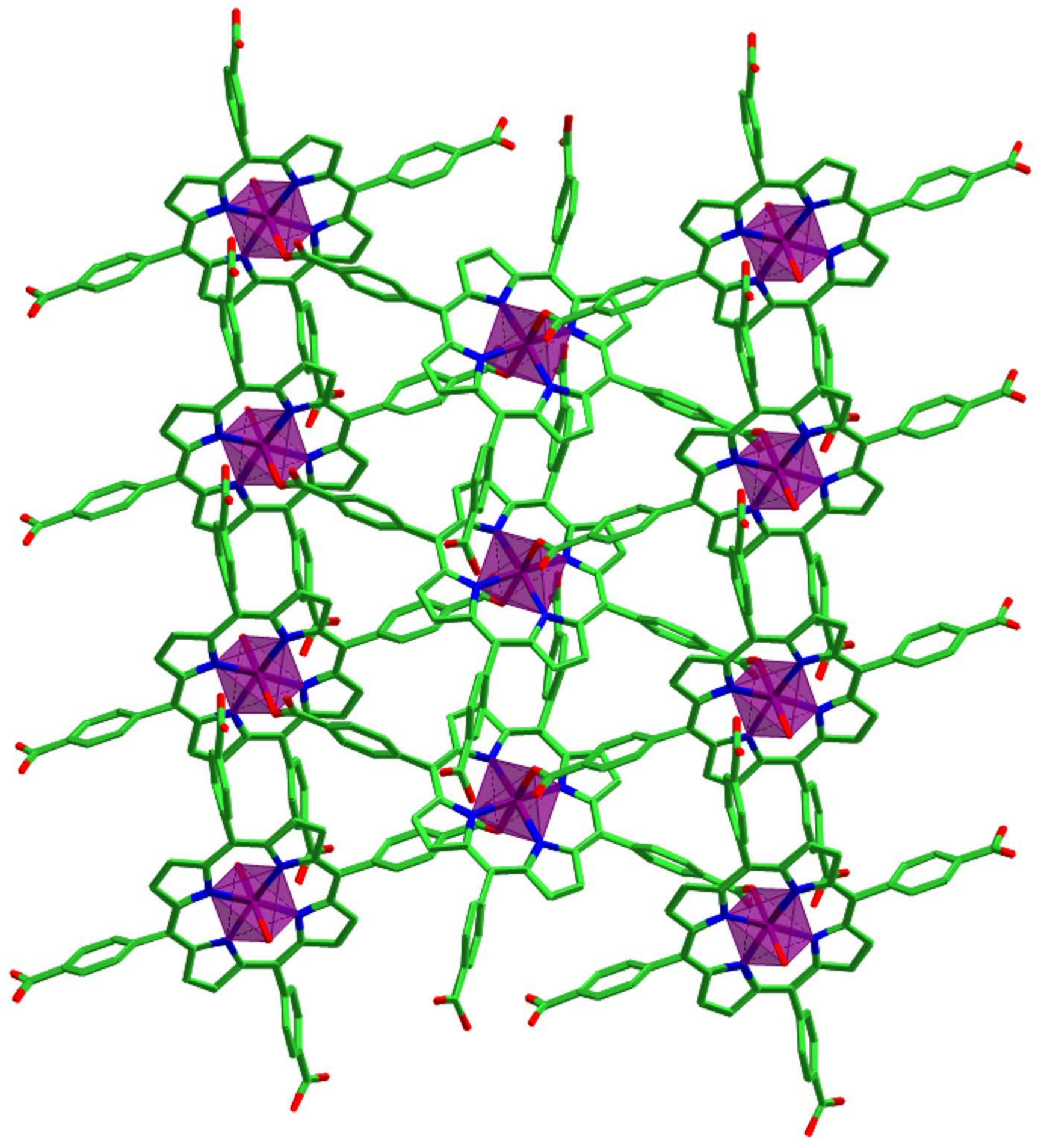

